\title{
Comparison of Alterations in c-fos and Egr-I (zif 268) Expression Throughout the Rat Brain Following Acute Administration of Different Classes of Antidepressant Compounds
}

\author{
David A Slattery*, 1,2,3, John A Morrow², Alan L Hudson', David R Hill', David J Nutt' and Brian Henry ${ }^{2}$ \\ 'Psychopharmacology Unit, Dorothy Hodgkin Building, Whitson Street, University of Bristol, Bristol, UK; ' Department of Pharmacology, Organon \\ Laboratories Ltd, Newhouse, Lanarkshire, Scotland, UK; ${ }^{3}$ Neuroscience Research, Novartis Institutes for BioMedical Research, Novartis Pharma \\ AG, Basel, Switzerland
}

\begin{abstract}
The majority of immediate-early gene (IEG) studies focus on a few key brain regions associated with the class of psychoactive compound being studied. Recently, using a meta-analysis of the c-fos literature, we demonstrated the utility of c-fos profiling to classify such compounds. The present study examined acute delivery of a range of antidepressant classes; fluoxetine, imipramine, LiCl, and mirtazapine. The dual aims were to study the IEG profiles of these varying classes of antidepressants throughout the rat brain and to compare the utility of c-fos or Egr-I as IEGs to classify clinically efficacious antidepressants. All antidepressants increased c-fos mRNA in the central amygdala, as previously shown, while c-fos was also increased in the anterior insular cortex and significantly decreased within the septum. Although acute antidepressant administration altered c-fos expression in a number of brain regions, Egr-I expression was only significantly altered in the central amygdala, suggesting that Egr-I may not be as useful a marker to investigate acute antidepressant treatment. The fact that these drugs, including the previously unclassified antidepressant mirtazapine, share a number of common loci of activation, which are implicated by human and animal studies in depression, adds further support to the use of IEG mapping to classify psychoactive compounds.
\end{abstract}

Neuropsychopharmacology (2005) 30, 1278-1287, advance online publication, 6 April 2005; doi:10.1038/sj.npp. 13007 I7

Keywords: c-fos; Egr-I; antidepressant; fluoxetine; mirtazapine; LiCl

\section{INTRODUCTION}

Since their discovery in the late 1980 s, cellular protooncogenes (Nishina et al, 1990; Sagar et al, 1988; Zerial et al, 1989) have become widely utilized tools to examine the effect of an acute stimulus; pharmacological or sensory (Beckmann and Wilce, 1997; Herdegen and Leah, 1998; Ziolkowska and Przewlocki, 2002). These transcription factors are also referred to as immediate-early genes (IEG) (Herrera and Robertson, 1996) and can be detected using immunohistochemistry (Dragunow and Faull, 1989) or in situ hybridization (Ziolkowska and Przewlocki, 2002) with members of the Fos- and Early growth response (Egr)-

*Correspondence: Dr DA Slattery, Current address: Nervous Systems Research, Novartis Pharma AG, Postfach, Basel CH-2002, Switzerland, Tel: +4I 6 I 3242042, Fax: + 4 I 61324 4502,

E-mail: david_anthony.slattery@novartis.com

Received 3 May 2004; revised 4 January 2005; accepted 7 February 2005

Online publication: I 4 February 2005 at http://www.acnp.org/citations/ NPP02 | 405040209/default.pdf families being among the most extensively studied. Egr-1 (also known as zif268, Krox-24, NGFI-A) has been extensively used to study neuronal responses to sensory stimuli and, unlike $c$-fos, exhibits a high basal expression (Beckmann and Wilce, 1997). Both IEGs are considered to reflect neuronal activity due to their function of controlling gene transcription via their protein forms binding to regulatory sites on DNA (Beckmann and Wilce, 1997; Chaudhuri, 1997; Herdegen and Leah, 1998; Hoffman and Lyo, 2002).

Owing to their utility as neuronal markers, IEGs have been used to examine numerous psychoactive compounds in an effort to understand the mechanism of action of these drugs. Despite the availability of a number of successful antidepressants, the pathology of depression remains unclear. All current drugs have a delayed onset of action and a primary mechanism of action to increase monoamine levels in the brain (see Slattery et al (2004) for a review). Although chronic administration of antidepressants is required for clinical benefit, acute IEG induction can give insight into their mechanisms as it reflects longer-term 
alterations in cellular phenotype and provides insight into the brain regions affected by antidepressants (for reviews see Beckmann and Wilce, 1997; Dragunow and Faull, 1989; Herdegen and Leah, 1998; Herrera and Robertson, 1996). The use of IEG profiling can help to elucidate those brain regions that are activated by acute antidepressant administration.

There are a number of considerations to take into account when using IEGs as neuronal activity markers, such as their transient response. Time course studies have demonstrated that $c$-fos mRNA is rapidly induced, within 30-60 min of an acute challenge and c-Fos protein after 90-120 min (Torres et al, 1998; Zangenehpour and Chaudhuri, 2002). Both mRNA and protein expression return to baseline after $6 \mathrm{~h}$. Egr-1 expression is less transient, showing similar induction responses to that of $c$-fos but levels remain elevated for up to $6 \mathrm{~h}$ following a stimulus (Zangenehpour and Chaudhuri, 2002). A major drawback of IEGs is that certain brain regions do not basally express a particular IEG, while other studies have shown that a wide variety of stimuli do not induce $c$-fos in certain brain regions such as the substantia nigra (Chaudhuri, 1997; Labiner et al, 1993); although recently caffeine has been demonstrated to increase Fos in this region (Singewald et al, 2003). This concern demonstrates the benefit of employing a number of IEGs to study the response to an acute stimulus, as a lack of induction of one gene may not necessarily mean a lack of neuronal activity. Further, despite Egr-1 and $c$-fos sharing a number of common activation pathways there are a number of differences that influence inducibility (see Herdegen and Leah (1998) for details). Egr-1 belongs to the class of zincfinger protein IEGs while $c$-fos is a member of the activator protein-1 (AP-1) family of IEGs (see Herdegen and Leah (1998) for a review). Egr-1 profiling has mainly been performed following sensory stimuli while that of $c$-fos has been used extensively following acute drug administration, although a number of drugs have been shown to alter Egr-1 expression (see Beckmann and Wilce, 1997).

The majority of IEG studies only focus on a small number of brain regions that are predicted to be affected by the drug, for example the nucleus accumbens for antipsychotics (see Sumner et al, (2004) for an overview). We recently performed a meta-analysis, which suggests that different therapeutic classes of psycho-active compounds can be differentiated based on their Fos profiles (Sumner et al, 2004). For example, all antidepressants increased c-fos expression in the central nucleus of the amygdala while the same was true of the nucleus accumbens for all antipsychotics analyzed (Sumner et al, 2004). Also, psychostimulant compounds displayed the most widespread $c$-fos activation, in numerous cortical and subcortical regions while anxiolytic compounds were shown to activate the fewest number of brain regions of the four classes of psychoactive drugs analyzed (Sumner et al, 2004).

Therefore, we determined to examine the effect of acute antidepressant treatment on Egr-1 and c-fos mRNA expression to determine whether different classes of antidepressants displayed similar or differential induction of the IEGs. The rationale for using both Egr-1 and c-fos in the present study was due to the different induction pathways of these genes, as well as the fact that basal Egr-1 expression has been demonstrated to be under noradrenergic control
(O'Donovan et al, 1999). Therefore, given the study of serotonergic and noradrenergic antidepressants, we determined to study if there would be similar or differential induction of $c$-fos and Egr-1 mRNA. Additionally, a number of studies have been performed, which demonstrate that there is differential regulation of Egr-1 and c-fos following acute antipsychotic administration (Cochran et al, 2002), therefore we determined to analyze this in relation to antidepressant administration. A range of different classes of antidepressants were examined, as well as the mood stabilizer $\mathrm{LiCl}$ (which also augments antidepressant administration and is used as a prophylactic treatment for depression; Fawcett, 2003), to determine whether there was a correlation in their IEG profiles and a wide number of brain regions, many of which were implicated in depression from both animal and human studies were analyzed, as well as a number of regions not previously implicated.

\section{MATERIALS AND METHODS}

\section{Animals and Experimental Procedure}

Male Sprague-Dawley rats (230-250 g, Harlan Olac, UK) were housed in groups of six on a $12 \mathrm{~h}$ light/dark cycle at $22 \pm 2^{\circ} \mathrm{C}$ and given free access to tap water and food. All animals received a single intraperitoneal (i.p.) injection of vehicle or psychoactive drug ( $n=6$ per group). Drugs and doses included $\mathrm{LiCl}$ (a mood stabilizer; $75 \mathrm{mg} / \mathrm{kg}$ ), mirtazapine (a noradrenaline and serotonin-selective antidepressant; $2 \mathrm{mg} / \mathrm{kg}$ ), fluoxetine (a selective serotonin $(5-\mathrm{HT}$ ) reuptake inhibitor (SSRI), $5 \mathrm{mg} / \mathrm{kg}$ ), or imipramine (a tricyclic antidepressant (TCA) inhibits NA and 5-HT reuptake; $15 \mathrm{mg} / \mathrm{kg}$ ) based on previous $c$-fos experiments (Lamprecht and Dudai, 1995; Morinobu et al, 1997; Torres et al, 1998). The exception was mirtazapine, for which there were no previous IEG studies and this dose was selected on behaviorally active doses in male rats (de Boer, 1996). All drugs were dissolved in 5\% mulgofen EL-719 (a detergent which improves solubility; GAF, Ltd, Manchester, UK), in a $0.9 \%$ saline solution and administered at $1 \mathrm{ml} / \mathrm{kg}$. Vehicle controls were injected with a 5\% mulgofen EL-719 in 0.9\% saline solution. At $45 \mathrm{~min}$ postinjection, rats were killed in a $\mathrm{CO}_{2}$-chamber and the brains rapidly removed and then snap-frozen in isopentane, cooled on dry-ice to $-32^{\circ} \mathrm{C}$. All animal experiments were carried out in accordance with the UK Animals (Scientific Procedures) Act, 1986.

\section{Tissue Processing}

Serial brain coronal sections $(20 \mu \mathrm{m})$ from 4.7 to $-10.3 \mathrm{~mm}$, in seven series of slides comprising 13 slides in each series were cut on a cryostat at $-18^{\circ} \mathrm{C}$ and thaw-mounted on to Superfrost Plus electro-statically charged nuclease-free slides (VWR). See Figure 1 for schematic diagram of brain levels sectioned and brain regions analyzed and the manner in which they were quantified (Paxinos and Watson, 1986). Sections were stored at $-80^{\circ} \mathrm{C}$ until required for processing. The sections were thawed at room temperature for $30 \mathrm{~min}$ then fixed in $4 \%$ paraformaldehyde in phosphate-buffered saline (PBS), rinsed and acetylated in acetic anhydride in $\mathrm{PBS}(\mathrm{pH}$ 8). After rinsing, the sections were dehydrated 
in an ascending series of ethanol (70, 80, 95, and 100\%) and stored under ethanol (95\%) at $4{ }^{\circ} \mathrm{C}$ until required for in situ hybridization (Henry et al, 1999). All solutions were prepared in diethylpyrocarbonate (DEPC)-treated water.

\section{Probe Labelling}

Two 48-base antisense oligonucleotide probes were designed to target different, nonoverlapping sequences of rat c-fos mRNA (NCBI Genbank Accession Number: X06769).

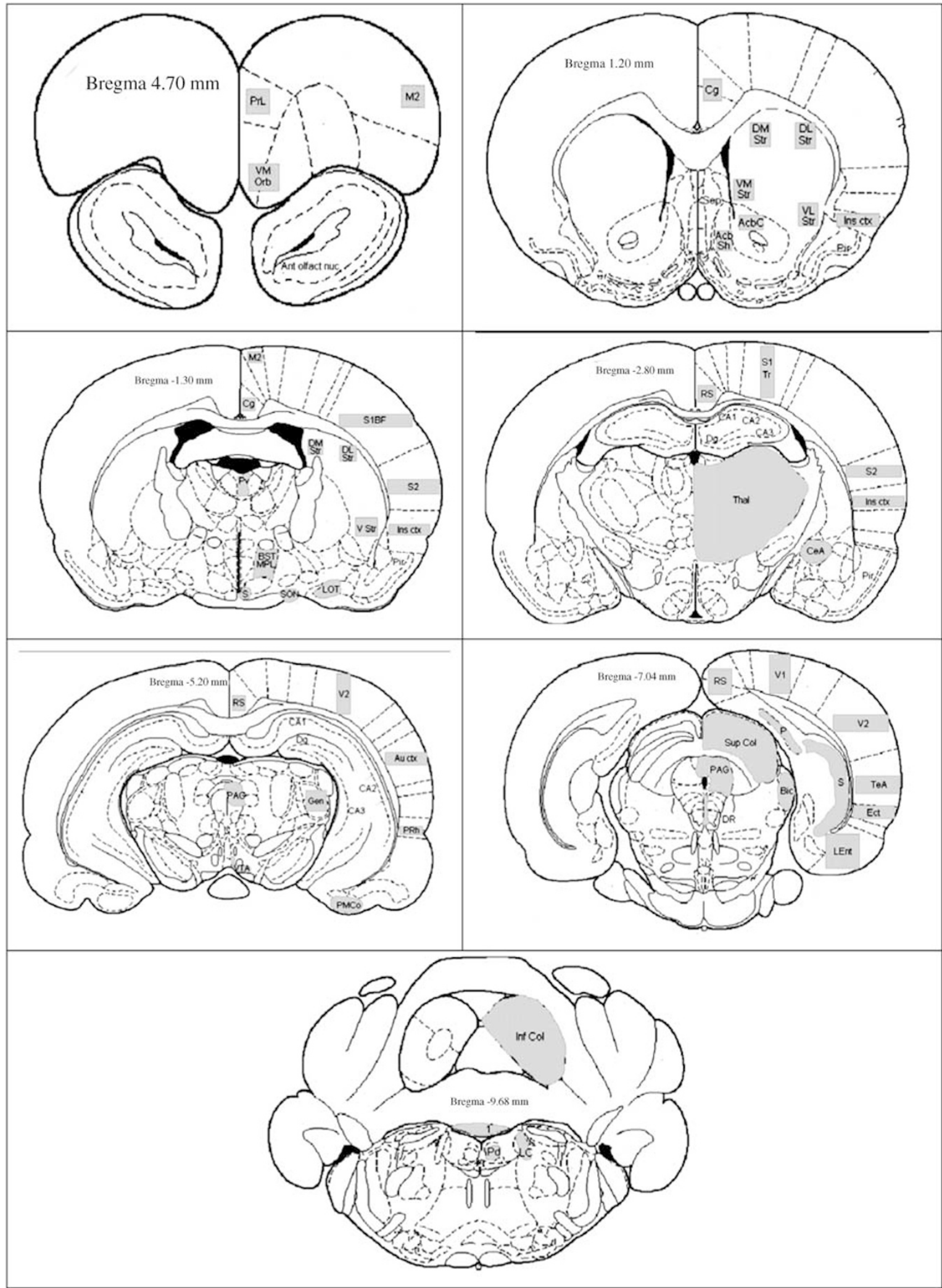


Probe 1 was complementary to bases 1001-1048 (probe sequence: $5^{\prime}$-GGC TCC CAG TCT GCT GCA TAG AAG GAA CCA GAC AGG TCC ACA TCT GGC-3'). Probe 2 was complementary to bases 141-188 (probe sequence: $5^{\prime}$-ACT GCA GCG GGA TGA CGC CTC GTA GTC CGC GTT GAA ACC CGA GAA-3'). One 45-base antisense oligonucleotide probe was designed to target rat Egr-1 mRNA (NCBI Genbank Accession Number M18416; probe sequence: 5'TGG GAG CCC GAC TGA GTG GCG AAG GCT TTG ATA GTG GAT AGT GGA-3'). Using the NCBI Basic Local Alignment Search Tool (BLAST; Altschul et al, 1990), the sequences were assessed for homology with other sequences and found to be specific for their respective transcripts. The synthetic oligonucleotide probes were synthesized by Life Technologies (Gibco, BRL, UK). Each oligonucleotide probe, was $3^{\prime}$-endlabelled with $\left[{ }^{33} \mathrm{P}\right] \mathrm{dATP}$ as previously described (Henry et al, 1999; Sumner et al, 2004). The labelled probe was then added to 'maximalist' hybridization buffer to give a final concentration of $0.5 \mathrm{pmol} / \mathrm{ml}$ hybridization solution (Henry et al, 1999). The final hybridization buffer was used the day it was prepared.

\section{In Situ Hybridization}

Labelled hybridization solution was pipetted on to each slide and placed in a hybridization box ( $150 \mu$ l per slide), which were then covered with Hybrislips (Sigma) and incubated in a hybridization oven at $42^{\circ} \mathrm{C}$ overnight. Following the incubation, the Hybrislips were floated off using $2 \times$ SSC solution and the slides were placed in racks for further processing as previously described (Henry et al, 1999; Sumner et al, 2004). Once dry the sections were exposed to X-ray film (BioMax MR-1, Kodak) under 'safe' red light conditions for 7 (Egr-1) or 14 (c-fos) days. An autoradiographic $\left[{ }^{14} \mathrm{C}\right]$ micro-scale (Amersham) of known radioactivity (range $31-833 \mathrm{nCi} / \mathrm{g}$ ) was also placed in each cassette to allow conversion of the optical density measurements to $\mathrm{nCi} / \mathrm{g}$. The films were then developed under 'safe' light conditions.

\section{Acetylcholinesterase Activity}

In order to assist histological verification of the brain regions analyzed, sites of acetylcholinesterase activity were examined. Untreated cryostat sections were removed from the $-80^{\circ} \mathrm{C}$ freezer and thawed to room temperature for $1 \mathrm{~h}$ before use. Acetylcholinesterase incubating medium $(13 \mathrm{ml} 0.1 \mathrm{M}$ acetate buffer, $2 \mathrm{ml} 0.03 \mathrm{M}$ cupric sulfate, $4 \mathrm{ml} \mathrm{dH}_{2} \mathrm{O}$ and $12 \mathrm{mg}$ ethopropazine and $0.01 \mathrm{~g}$ acetylthiocholine iodide) was prepared immediately before use and slides were incubated for $2 \mathrm{~h}$ at room temperature in the dark and then washed in $\mathrm{dH}_{2} \mathrm{O}$ for $1 \mathrm{~min}$. The sections were then subjected to a $1 \%$ ammonium sulfide solution (prepared in $\mathrm{dH}_{2} \mathrm{O}$ ) for $1 \mathrm{~min}$, to visualize the sites of acetylcholinesterase activity. The slides were then rinsed in several $\mathrm{dH}_{2} \mathrm{O}$ incubations and allowed to air-dry, then dehydrated and mounted in DPX. This method was adapted from Bancroft and Stevens (1996).

\section{Data Analysis and Statistics}

Densitometric analysis of autoradiographs was performed using a Microcomputer Imaging Device (MCID, InterFocus, Ltd, Haverhill, Suffolk, UK) system. Bilateral relative optical density (ROD) measurements were taken from triplicate sections from each animal $(n=6)$ and converted to $\mathrm{nCi} / \mathrm{g}$ by creating a standard curve from the $\left[{ }^{14} \mathrm{C}\right]$-standards. The brain regions analyzed are shown in Figure 1. The majority of brain regions were chosen based on those that have been implicated in major depression from human neuroimaging studies and from preclinical studies involving lesions and prior IEG studies (Drevets, 1999, 2000, 2001; Kirby and Lucki, 1997; Ongur and Price, 2000; Ronan et al, 2000; Slattery et al, 2004; Sumner et al, 2004). These studies have revealed that numerous brain regions that have previously not been implicated in depression seem to play roles; therefore, we also determined to examine a number of other brain regions, at the same bregma coordinates as those implicated in depression. In total, over 50 brain regions were analyzed (not all regions are shown) for alterations in both $c$-fos and Egr-1. In a small number of brain regions, the data shown for imipramine, mirtazapine and fluoxetine have been previously represented in Sumner et al (2004) in a format only detailing global alteration in $c$-fos mRNA compared with vehicle as opposed to the actual raw values presented here. A one-way ANOVA with Dunnett's posthoc test was performed for each brain region analyzed to determine statistical significance of any drug-induced changes in mRNA using GraphPad Prism v3.02.

\section{RESULTS}

In situ hybridization utilizing two probes complementary to the rat $c$-fos or one probe complementary to the rat Egr-1 transcript following acute antidepressant administration demonstrated differing expression profiles for each treatment group. Each of the different drug-treatment groups

\footnotetext{
Figure I Schematic representation of the seven brain levels sectioned from 4.7 to - 10 mm relative to bregma. In all, 13 slides were collected at each level with each slide containing three $20 \mu \mathrm{m}$ serial brain sections. In each schematic, the brain regions analyzed are shown; where those in grey shade represent the area quantified and not in grey are regions that were quantified using the whole region. Schematics adapted from Paxinos and Watson (I986). Abb: M2 ctx, secondary motor cortex; PrL ctx, prelimbic cortex; VM Orb, ventromedial orbital cortex; AON, anterior olfactory nucleus; Pir, piriform cortex; Cg, cingulate cortex; Ins, insular cortex; DM Str, dorsomedial striatum; DL Str, dorsolateral striatum; VL Str, ventrolateral striatum; VM Str, ventromedial striatum; AcbC, nucleus accumbens core region; AcbSh, nucleus accumbens shell region; Sep, septum; SI BF, primary somatosensory cortex, barrel field;;S2, secondary somatosensory cortex; Pv, anterior paraventricular thalamic nucleus; $\vee$ Str, caudal ventral striatum; LOT, nucleus of the lateral olfactory tract; SON, supraoptic nucleus; BSTMPL, nucleus of the stria terminalis, medial division, posterolateral part; $\mathrm{S}$, suprachiasmatic nucleus; RS, retrosplenial cortex; SITr, primary somatosensory cortex, trunk region; CAI, field CAI of hippocampus; CA2, field CA2 of hippocampus; CA3, field CA3 of hippocampus; Dg, dentate gyrus; CeA, central amygdaloid nucleus; Thal, thalamus; V2, secondary visual cortex, lateral area; Au ctx, primary auditory cortex; PRh ctx, perirhinal cortex; PAG, periaqueductal gray; VTA, ventral tegmental area; Gen, geniculate nucleus; PMCo, posteromedial cortical amygdaloid nucleus; VI, primary visual cortex; TeA, temporal association cortex; Ect, ectorhinal cortex; LEnt, lateral entorhinal cortex; DR, caudal dorsal raphé; Sup Col, superior colliculus; BIC, nucleus of the brachium of the inferior colliculus; S, subiculum; P, post-subiculum; Inf col, inferior colliculus; LC, locus coeruleus; Pd, posterodorsal tegmental nucleus.
} 
displayed different regulation of $c$-fos and Egr-1 mRNA expression, with both increased and decreased levels compared with vehicle observed. In the present study, $c$ fos expression in the vehicle control groups appeared to be elevated compared with a number of previous studies (Cochran et al, 2002; Singewald and Sharp, 2000; Torres et al, 1998). However, this may be due to employing the detergent mulogfen in the solutions and would therefore be present in all treatment groups.

\section{Brain Regions with Common Profile}

There were only three brain regions out of more than 50 examined for alterations in $c$-fos and Egr-1 expression (not all data are shown), where acute administration of all antidepressants exhibited a common $c$-fos profile; anterior insular cortex, septum, and central amygdala (see Figure 2). All antidepressants significantly increased $c$-fos expression in the anterior insular cortex (imipramine 38\%, mirtazapine $50 \%$, fluoxetine $61 \%$, and $\mathrm{LiCl} 41 \%$ increase compared with vehicle) and central amygdala (imipramine $187 \%$, mirtazapine $131 \%$, fluoxetine $252 \%$, and $\mathrm{LiCl} 540 \%$ increase
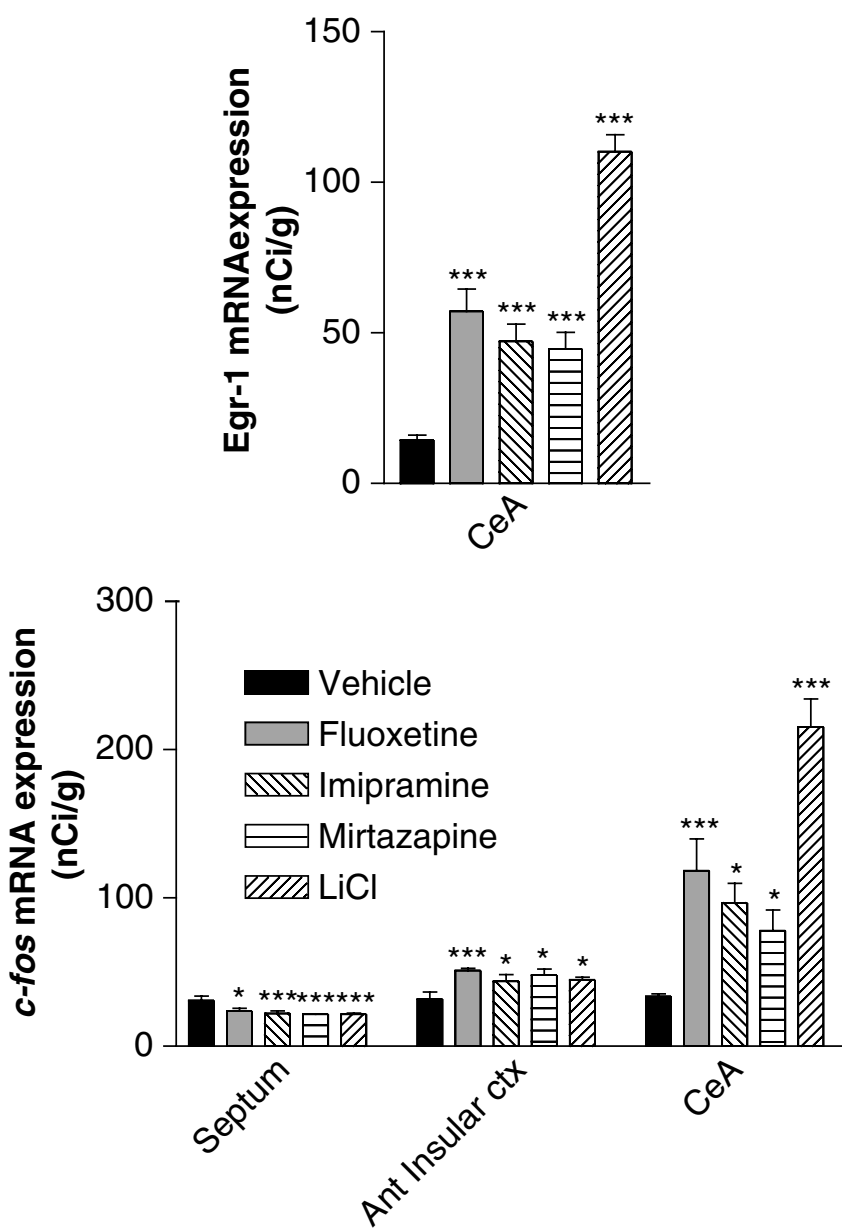

Figure 2 IEG expression 45-min following acute i.p. vehicle, fluoxetine ( $5 \mathrm{mg} / \mathrm{kg})$, imipramine ( $15 \mathrm{mg} / \mathrm{kg})$, mirtazapine $(2 \mathrm{mg} / \mathrm{kg})$, or LiCl $(75 \mathrm{mg} / \mathrm{kg})$ administration in the central amgydala (CeA), septum, and anterior insular cortex (Ant Insular ctx). Data represent mean $\pm \operatorname{SEM}(n=6)$. One-way ANOVA with Dunnett's post hoc test was performed $* P<0.05$ and **** $P<0.00$ I compared with vehicle. compared with vehicle), whereas all significantly decreased levels in the septum (imipramine 29\%, mirtazapine 30\%, fluoxetine 23\%, and LiCl 29\% decrease compared with vehicle). Furthermore, all antidepressants also increased Egr-1 expression in the central amygdala (imipramine $227 \%$, mirtazapine 209\%, fluoxetine 296\%, and $\mathrm{LiCl} 664 \%$ increase compared with vehicle; $P<0.001$; Figure 2), which was the only brain region analyzed where acute antidepressant administration altered Egr-1 expression (see Figure 2 and Table 1). Acetylcholinesterase activity was performed to histologically verify the amygdaloid site and demonstrated that the central amygdala was the locus of IEG activation (see Figure 3).

\section{Further Alterations of $c$-fos Following Acute Antidepressant Administration}

At $45 \mathrm{~min}$ following acute fluoxetine administration $c$-fos mRNA expression was significantly increased in the ventromedial orbital cortex $(P<0.05)$, ventromedial striatum $(P<0.05)$, nucleus accumbens core region $(P<0.05)$, nucleus accumbens shell region $(P<0.001)$, and in the anterior cingulate cortex $(P<0.001$; see Figure 4$)$. In the striatal and cortical regions, fluoxetine was the only one of the drugs tested which altered $c$-fos mRNA expression, whereas in the nucleus accumbens core and shell regions mirtazapine and $\mathrm{LiCl}$ also increased $c$-fos levels $(P<0.001)$.

The locus coeruleus and the dorsal raphe are the main sites of noradrenergic and serotonergic origin in the central nervous system (CNS), respectively. In the locus coeruleus, despite a trend towards an increase of $c$-fos expression following mirtazapine or $\mathrm{LiCl}$ compared with vehicle, only fluoxetine administration reached significance $(P<0.05$; Table 2). Similarly, no effect of treatment was observed in the caudal dorsal raphé (Table 2). Administration of fluoxetine, imipramine $(P<0.001)$ or $\mathrm{LiCl}(P<0.05)$, but not mirtazapine, increased $c$-fos expression in the perirhinal cortex (Table 2). No alterations in $c$-fos expression were observed in the CA1 field of the hippocampus (Table 2). However, imipramine, mirtazapine, and $\mathrm{LiCl}$ administration downregulated mRNA levels in the subiculum (Table 2). The most robust increase in $c$-fos expression was in the supraoptic nucleus following $\mathrm{LiCl}$ treatment; a 10-fold increase was observed (Table 2). Despite a trend towards an increase in this brain region following fluoxetine administration, this did not reach significance $(P>0.05)$.

\section{DISCUSSION}

The aims of the present study were two-fold: firstly to provide comprehensive analyses of brain regions where acute antidepressant administration alters $c$-fos and Egr-1 expression and secondly to compare the induction profiles of the two IEGs and identify regions of commonality with regard to regional activation.

Overall a number of brain regions showed induction of $c$ fos following acute antidepressant administration, while Egr-1 mRNA was only altered in one brain region analyzed; the central amgydala (see Figure 2 and Table 1). A similar low induction of Egr-1 mRNA following acute antipsychotic treatment has previously been reported in a study examin- 
Table I Levels of Egr-I mRNA Expression in Identified Brain Regions 45-min Following Acute Administration of Vehicle, Fluoxetine (5 mg/ $\mathrm{kg})$, Imipramine ( $15 \mathrm{mg} / \mathrm{kg})$, Mirtazapine (2 mg/kg), or LiCl $(75 \mathrm{mg} / \mathrm{kg} ; \mathrm{n}=6)$

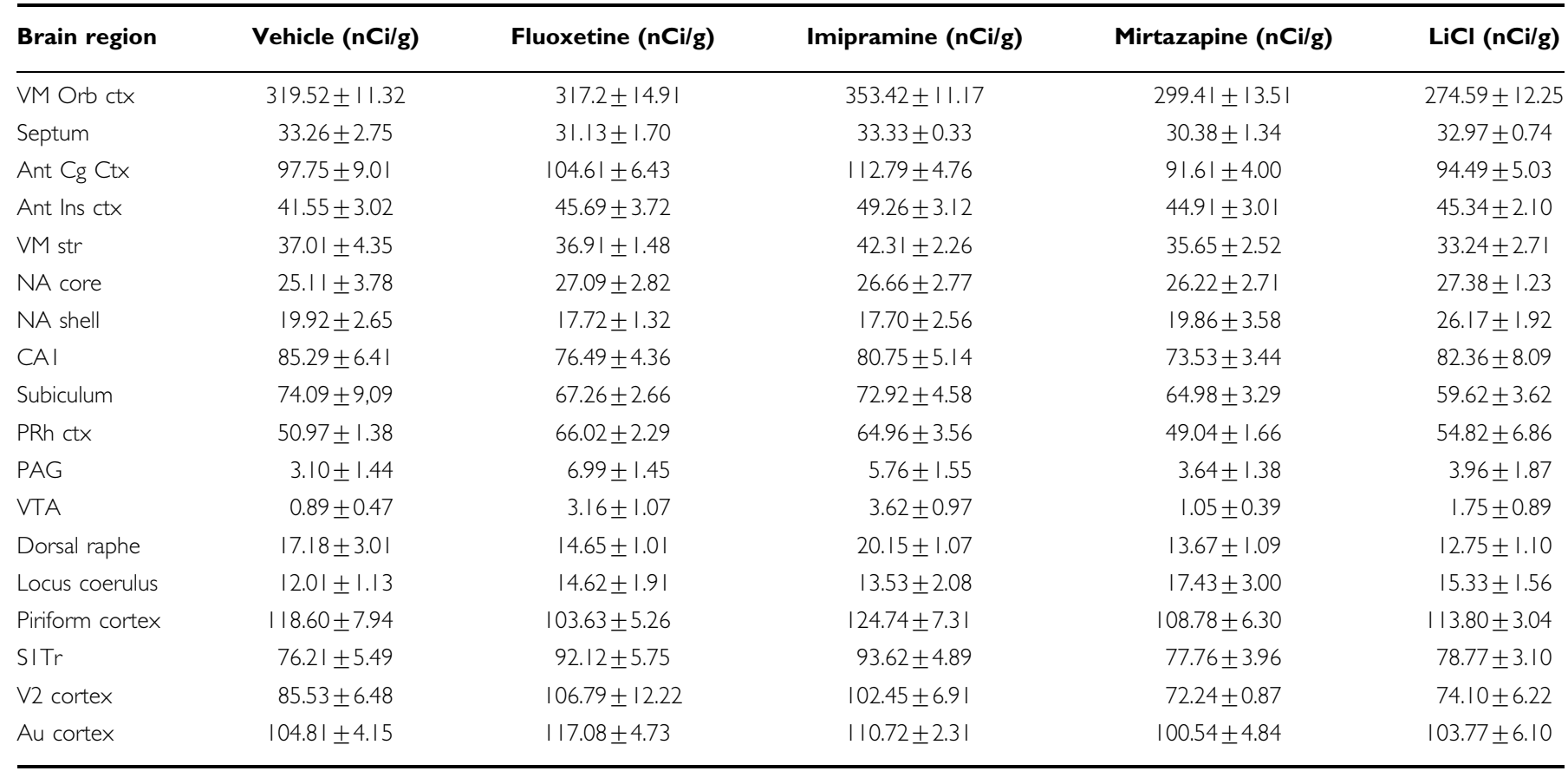

Data represent mean \pm SEM, one-way ANOVA with Dunnett's post hoc test was performed. VM Orb ctx, ventromedial orbital cortex; Ant Cg Ctx, anterior cingulate cortex; Ant Ins ctx, anterior insular cortex; VM Str, ventromedial striatum; NA, nucleus accumbens; PRh ctx, perirhinal cortex; PAG, periaqueductal gray; VTA, ventral tegmental area; SITr, primary somatosensory cortex trunk region; V2 cortex, secondary visual cortex; Au cortex, auditory cortex.
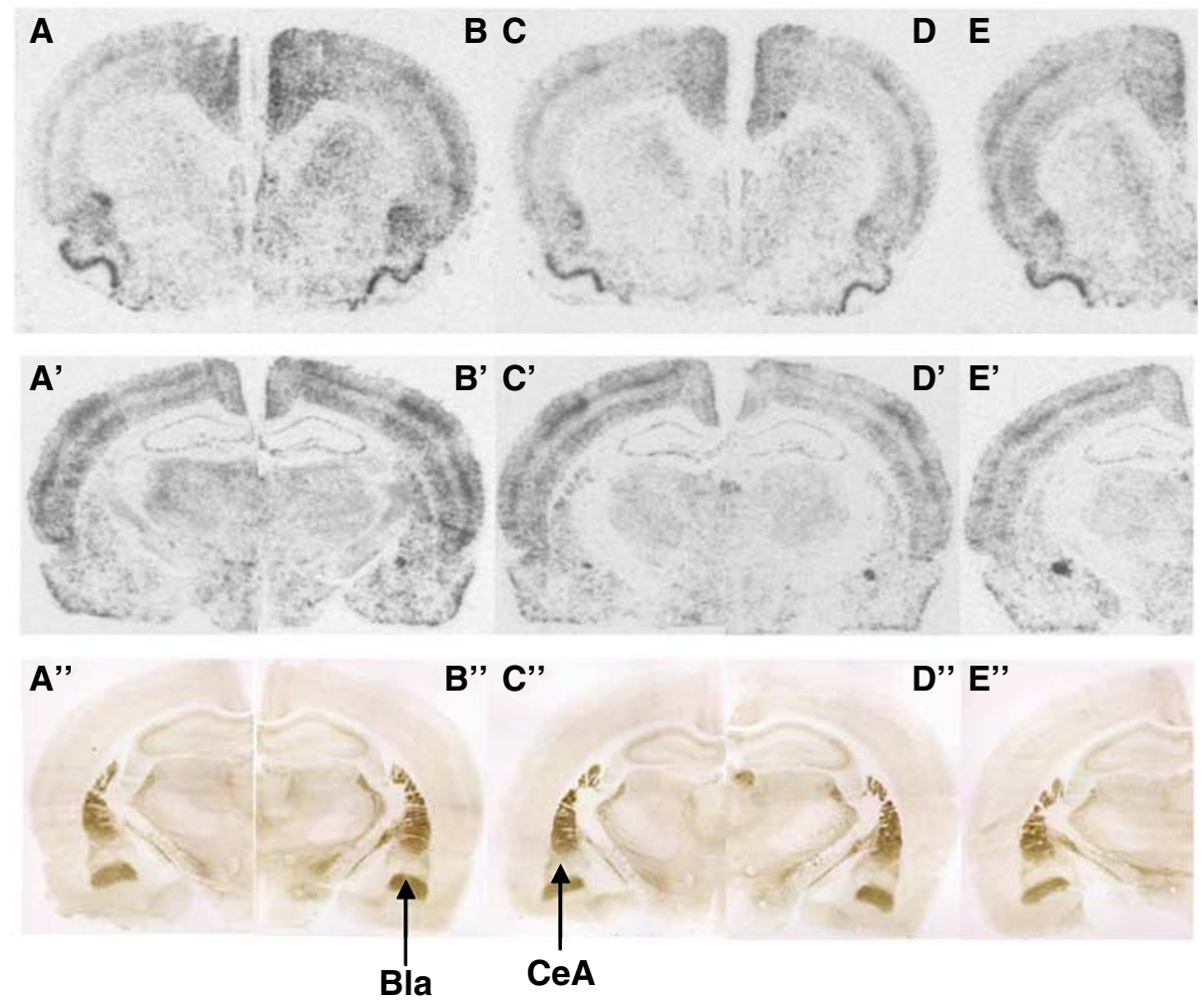

B" C"

D" E"

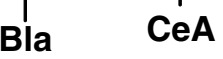

Figure 3 Representative left or right hemisphere coronal c-fos autoradiographs 45-min following acute administration of vehicle (A and $\left.A^{\prime}\right)$, fluoxetine $\left(5 \mathrm{mg} / \mathrm{kg} ; \mathrm{B}\right.$ and $\left.\mathrm{B}^{\prime}\right)$, imipramine $\left(15 \mathrm{mg} / \mathrm{kg} ; C\right.$ and $\left.\mathrm{C}^{\prime}\right)$, mirtazapine $\left(2 \mathrm{mg} / \mathrm{kg} ; \mathrm{D}\right.$ and $\left.\mathrm{D}^{\prime}\right)$, or $\mathrm{LiCl}\left(75 \mathrm{mg} / \mathrm{kg} ; \mathrm{E}\right.$ and $\left.\mathrm{E}^{\prime}\right)$ displaying alterations in the anterior insular cortex and septum or central amygdala, respectively. Corresponding acetylcholinesterase images $\left(A^{\prime \prime}-E^{\prime \prime}\right)$ enabled delineation between the central amygaloid nucleus (CeA) and basolateral amygaloid nucleus (BIA), which when overlaid with the autoradiograms shows the CeA as the site of c-fos induction. 
ing both $c$-fos and Egr-1 (Cochran et al, 2002). A possible explanation for this is the different intracellular pathways by which, $c$-fos and Egr-1 are induced (see Introduction). Egr-1 tends to be used as a marker following sensory stimuli, although a number of drugs have been demonstrated to activate Egr-1 (see Beckmann and Wilce (1997) for a review), whereas $c$-fos is used more extensively in both sensory and drug administration paradigms. Therefore, the comparison of $c$-fos and Egr-1 profiles demonstrated that Egr-1 is not as versatile as $c$-fos as an IEG to study neuronal induction following acute antidepressant treatment.

\section{Activation of Common Brain Regions by all Antidepressants}

All antidepressants tested increased $c$-fos levels in the anterior insular cortex and central amygdala compared with vehicle, and decreased levels in the septum (Figure 2).

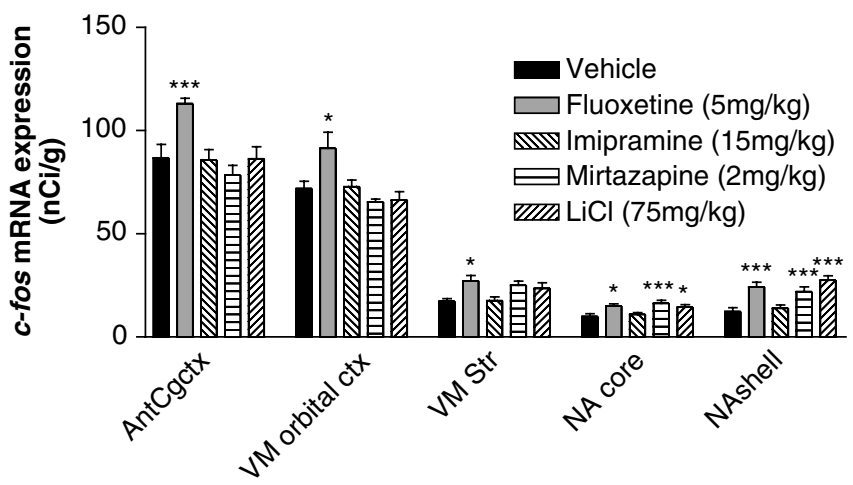

Figure 4 Alterations in c-fos expression in the anterior cingulate cortex (Ant Cg ctx), ventromedial orbital cortex (VM orbital ctx), VM striatum (VM Str), and nucleus accumbens (NA) core and shell regions. Data represent mean \pm SEM 45 min following acute administration of vehicle, fluoxetine $(5 \mathrm{mg} / \mathrm{kg})$, imipramine ( $15 \mathrm{mg} / \mathrm{kg})$, mirtazapine $(2 \mathrm{mg} / \mathrm{kg})$, or $\mathrm{LiCl}$ $(75 \mathrm{mg} / \mathrm{kg} ; n=6)$. One-way ANOVA with Dunnett's post hoc test was performed $* P<0.05$ and ${ }^{*} * * P<0.00$ I compared with vehicle
Additionally, the only brain region where Egr-1 mRNA expression was altered was in the central nucleus of the amygdala (CeA), and it was induced by all classes of antidepressants examined (see Figure 2). Intriguingly, these three brain regions have been linked with depression in human neuroimaging studies. These studies have demonstrated an increase in cerebral blood flow and glucose metabolism in the anterior insular cortex and amygdala in depressed patients (the resolution was insufficient to determine the subdivision within the amygdala; Drevets, 2000, 2001). Furthermore, the severity of depression appeared to correlate with cerebral blood flow (CBF) and glucose metabolism in the amygdala (Drevets et al, 1992). Rats exposed to fear-conditioned stimuli demonstrate a $53 \%$ increase in local $\mathrm{CBF}$, as measured by $\left[{ }^{14} \mathrm{C}\right]-$ iodoantipyrine autoradiography (LeDoux et al, 1983), and chronic antidepressant treatment normalizes the hyperactivity of the amygdala in both rats and humans (see Drevets (1999) for a review). Additionally, the central amygdala has previously been demonstrated to be the only common site of c-fos activation by antidepressants (Beck, 1995; Duncan et al, 1996). However, a number of other psychoactive compounds also elevate $c$-fos in this brain region (see Sumner et al, 2004). A previous study has similarly demonstrated that $\mathrm{LiCl}$ (Lamprecht and Dudai, 1995) induces Egr-1 expression in the central amygdala. This evidence, coupled with the present study, is suggestive that the central amygdala may be a locus of antidepressant activity as mirtazapine, whose effect on IEGs has not previously been documented, also elevates $c$-fos and Egr-1 in this brain region. However, methamphetamine $(40 \mathrm{mg} /$ $\mathrm{kg}$; Thiriet et al, 2001), diazepam (2.5 and $5 \mathrm{mg} / \mathrm{kg}$; Malkani and Rosen, 2000), and kainic acid-induced seizures (Gass et al, 1993) also induce Egr-1 expression in the central amygdala indicating that other stimuli can also lead to an increase in IEG expression in this area.

The Egr-1 mRNA induction evoked by the LiCl administration in the present study was significantly greater than all other treatments, as was also observed for $c$-fos. The

Table 2 Levels of c-fos mRNA Expression in Identified Brain Regions 45-min Following Injection of Vehicle, Fluoxetine (5 mg/kg), Imipramine (I5 mg/kg), Mirtazapine (2 mg/kg), or LiCl $(75 \mathrm{mg} / \mathrm{kg} ; n=6)$

\begin{tabular}{|c|c|c|c|c|c|}
\hline Brain region & Vehicle (nCi/g) & Fluoxetine (nCi/g) & Imipramine (nCi/g) & Mirtazapine (nCi/g) & $\mathrm{LiCl}(\mathrm{nCi} / \mathrm{g})$ \\
\hline $\mathrm{SON}$ & $26.83 \pm 3.18$ & $56.42 \pm 5.74$ & $33.60 \pm 2.76$ & $44.56 \pm 5.47$ & $285.89 \pm 37.92 * * * *$ \\
\hline VTA & $19.00 \pm 1.27$ & $28.64 \pm 2.15^{* * * * *}$ & $22.51 \pm 2.44$ & $18.83 \pm 0.79$ & $19.66 \pm 1.43$ \\
\hline PRh ctx & $54.12 \pm 1.05$ & $89.01 \pm 2.71$ 米*** & $67.99 \pm 2.62$ **** & $55.49 \pm 1.45$ & $61.82 \pm 2.02 *$ \\
\hline PAG & $25.57 \pm 1.57$ & $34.12 \pm 1.78^{* * * * *}$ & $29.05 \pm 1.66$ & $23.33 \pm 1.50$ & $24.79 \pm 2.34$ \\
\hline Dorsal raphe & $22.55 \pm 2.11$ & $27.31 \pm 1.58$ & $26.53 \pm 1.39$ & $24.58 \pm 0.90$ & $22.7 \pm 2.89$ \\
\hline Locus coerulus & $35.43 \pm 1.98$ & $52.79 \pm 3.56 *$ & $38.6 \pm 3.08$ & $47.47 \pm 3.38$ & $42.61 \pm 4.93$ \\
\hline CAI & $21.59 \pm 2.55$ & $20.41 \pm 1.13$ & $21.97 \pm 1.47$ & $19.05 \pm 1.22$ & $17.20 \pm 1.88$ \\
\hline Subiculum & $27.32 \pm 0.77$ & $25.41 \pm 0.47$ & $22.47 \pm 0.67^{*}$ & $22.19 \pm 2.00 *$ & $20.78 \pm 1.34^{* * *}$ \\
\hline Piriform cortex & $89.85 \pm 2.02$ & $77.75 \pm 3.36 *$ & $76.79 \pm 1.62$ **** & $80.35 \pm 3.51$ & $77.95 \pm 2.84 *$ \\
\hline SITr & $39.74 \pm 2.76$ & $50.26 \pm 2.26 *$ & $44.33 \pm 2.92$ & $34.66 \pm 1.74$ & $32.73 \pm 2.01$ \\
\hline V2 cortex & $71.73 \pm 3.59$ & $94.75 \pm 5.03^{* * * * * *}$ & $72.91 \pm 3.09$ & $56.41 \pm 2.03^{*}$ & $57.74 \pm 2.62 *$ \\
\hline Au cortex & $92.54 \pm 1.84$ & $107.00 \pm 5.28^{*}$ & $90.56 \pm 3.32$ & $81.97 \pm 2.84$ & $84.85 \pm 3.39$ \\
\hline
\end{tabular}

Data represent mean \pm SEM, one-way ANOVA with Dunnett's post-hoc test was performed $* P<0.05$, * $*$ P $<0.0$ I, and $* * * P<0.00 I$ compared with vehicle. SON supraoptic nucleus; VTA, ventral tegmental area; PRh ctx, perirhinal cortex; PAG, periaqueductal gray; SITr, primary somatosensory cortex trunk region; V2 cortex, secondary visual cortex; Au cortex, auditory cortex. 
reason for this is unclear. Spencer and Houpt (2001) demonstrated that $\mathrm{LiCl}$ induced $c$-fos as well as another transcription factor, inducible cAMP early repressor (ICER) mRNA, in the central amygdala, which is suggestive of a cAMP-dependent pathway. $\mathrm{LiCl}$ injection has been shown to phosphorylate MAP kinase in murine insular cortex and central amygdala $30 \mathrm{~min}$ after injection, which would lead to activation of the SRE in the promoter region of $c$-fos and Egr-1 genes. This may explain the high induction of the IEGs by $\mathrm{LiCl}$ in the central amygdala, as other antidepressants would be expected to only activate the cAMPdependent elements in the IEG promoters. Despite a trend of an increase in Egr-1 expression in the insular cortex following $\mathrm{LiCl}$ treatment this did not reach significance.

All antidepressants tested in the present trial significantly increased $c$-fos expression in the anterior insular cortex (Figure 2). Similar to the amygdala, human neuroimaging studies in familial major depressive disorder have demonstrated an elevated CBF and glucose metabolism in the anterior insula (Drevets, 2000, 2001). Furthermore, a role for this brain region in sleep control has been implied by studies in healthy volunteers, where an increase in metabolism in the insula from waking to REM sleep was demonstrated (Nofzinger et al, 2001). Additionally, the antidepressant bupropion treatment normalized this relationship in depressed patients (Nofzinger et al, 2001).

The septum is also believed to be an important brain region in animal models of depression (Kirby and Lucki, 1997). The helpless behavior in learned helplessness is thought to be related to 5-HT levels in the septum, as microinjection of 5-HT into the lateral septal nucleus reverses learned helplessness (Sherman and Petty, 1980). Indeed, Ronan et al (2000) demonstrated that rats that do not develop learned helplessness behavior had increased levels of 5-hydroxyindoleacetic acid (5-HIAA) in the lateral septum as measured by microdialysis. This also suggests that 5-HT levels are involved, as higher concentrations of 5HIAA possibly indicates increased 5-HT metabolism. A recent study reported decreased c-Fos in the lateral septal nucleus of learned helpless rats, and it was hypothesized that this may represent the deficient 5-HT transmission of these rats (Steciuk et al, 1999). Another animal model of depression, the forced swim test, has been demonstrated to increase c-Fos in the lateral septum, which is reversed by pretreatment with antidepressants (Duncan et al, 1996). Similarly, Salchner and Singewald (2002) have demonstrated that acute fluoxetine administration $(5$ or $10 \mathrm{mg} / \mathrm{kg}$ ) induced c-Fos expression in the ventral lateral septal nucleus and exposure to airjet stress potentiated the Fos expression following the higher dose only. Therefore, the fact that all drugs in the present study decreased stressinduced $c$-fos mRNA expression in the septum would appear to contradict the findings from the learned-helplessness study and airjet stressor study but corroborate those of the forced-swim test, although both of these studies examined protein expression rather than mRNA levels of the IEG.

\section{Most Robust Increase in $c$-fos mRNA}

The most robust induction of $c$-fos mRNA observed by any drug treatment was in the supraoptic nucleus following $\mathrm{LiCl}$ administration (Table 2). A 10-fold increase compared with vehicle, and five-fold compared with all other drugtreatments was seen. A likely explanation for this comes from the knowledge that the supraoptic nucleus is sensitive to osmotic balance (see Hussy et al (2000) for a review) and the injection of a large number of $\mathrm{Li}^{+}$ions may disrupt this balance. Despite a trend towards an increase following fluoxetine treatment, as previously reported by immunohistochemical studies (Torres et al, 1998), this did not reach significance compared with vehicle in the present study (Table 2).

\section{Brain Regions Activated Primarily by Fluoxetine}

Human neuroimaging studies have shown that in familial major depressive disorder there is abnormally elevated CBF and glucose metabolism in the orbital, ventral anterior cingulate cortex, anterior insular cortex, ventral striatum, amygdala, and medial thalamus (see Drevets (2000) for a review); all components of the orbitofrontal circuit. Strong $c$-fos mRNA induction was particularly noted throughout the dorsal and ventral striatum, including the nucleus accumbens core and shell regions (Figure 4). The ventral striatum also projects to the VTA and PAG, in which $c$-fos induction following fluoxetine administration was observed (Table 2). These regions have extensive reciprocal connections with the amygdala and are involved in social withdrawal, fear, and pain; behaviors associated with depression (Drevets, 2000, 2001). The current findings are suggestive that fluoxetine, one of the most commonly prescribed antidepressants, targets a number of brain regions after acute administration, which show abnormal metabolism in depressed patients. It is possible that fluoxetine administration only targets a few of the brain regions in this circuitry but due to reciprocal connections, the increase in neuronal activity in one region affects others. This possibility has been demonstrated for $c$-fos, which can be activated in neurons removed from the site of direct neuronal stimulus (Ziolkowska and Przewlocki, 2002). Other studies analyzing the anterior cingulate cortex have mainly focused on antipsychotics (clozapine $20 \mathrm{mg} / \mathrm{kg}$ ) and psychostimulant (PCP, amphetamine, caffeine, MK-801, and ketamine) compounds, which have been shown to increase $c$-fos expression in this region (see Sumner et al, 2004). However, psychostimulants show a very pronounced cortical, and indeed overall, induction of $c$-fos, which may reflect the nature of these compounds. Nevertheless, it is striking that acute fluoxetine targets so many brain regions known to be associated with depression, especially as very few structures other than those mentioned were observed to be altered by fluoxetine compared with vehicle (piriform cortex, suprachiasmatic nucleus, primary somatosensory cortex, secondary visual cortex, auditory cortex, data not shown).

\section{Locus Coeruleus and Caudal Dorsal Raphé Nucleus}

Another important brain region in depression is the locus coeruleus, which is the major origin of noradrenergic projections in the CNS (Holets, 1990). Although the fluoxetine-evoked increase within the locus coeruleus was 
significant, all other antidepressant groups except imipramine demonstrated a nonsignificant trend towards elevated c-fos mRNA expression in this region (Table 2). Previous studies that have analyzed this brain region have shown that the antidepressants desipramine $(10 \mathrm{mg} / \mathrm{kg})$, tranylcypromine $(7.5 \mathrm{mg} / \mathrm{kg})$, and bupropion $(20 \mathrm{mg} / \mathrm{kg})$ significantly elevate $c$-fos (Beck, 1995). That all antidepressants show a trend towards an increase in neuronal activity in this region is not surprising given that most increase noradrenergic neurotransmission (Frazer, 2000). Similar findings were observed in this study with the caudal dorsal raphé, as all drugs except $\mathrm{LiCl}$ displayed a trend towards an increase in c-fos expression. However, only one previous report concerning the caudal dorsal raphe has come to light, which also demonstrated that fluoxetine $(10 \mathrm{mg} / \mathrm{kg})$ did not alter $c$-fos expression in the caudal dorsal raphé (Lino-deOliveira et al, 2001).

Interestingly, given that acute antidepressant treatment is known to induce anxiogenic-like responses acutely in animals, a number of the regions where $c$-fos was elevated by fluoxetine are coincident with areas that are commonly activated by different anxiogenic compounds. For example, Singewald et al (2003) demonstrated that acute administration of the anxiogenics caffeine, $m$-chlorophenylpiperazine (mCPP), yohimbine, and FG-7142 (benzodiazepine inverse agoinst) increased c-Fos expression in the septum and central nucleus of the amygdala, which are the two areas that shared a common profile in the present study. This suggests that the similarity between the $c$-fos activation profiles may, in part, be due to the anxiogenic-like effect of antidepressant. However, the posterior agranular insular cortex was activated by all but one compound (MCPP; Singewald et al, 2003) but not by any of the antidepressants (data not shown), although the anterior insular cortex was activated by all antidepressants in this study (Figure 2). Additionally, it should be noted that although the anxiogenic compounds have been shown to increase c-Fos expression in the prelimbic cortex, secondary somatosensory cortex, and bed nucleus of the stria terminalis (Singewald et al, 2003), we did not find alteration in these regions following antidepressant administration (data not shown).

In conclusion, this study provides further evidence supporting the use of IEG mapping for the classification of novel compounds and identification of brain regions affected by acute drug administration (see Sumner et al, 2004). Comparison of the activation profiles of $c$-fos and Egr-1 mRNA expression following acute antidepressant administration demonstrated that Egr-1 expression is only altered within the central amygdala, suggesting that Egr-1 does not provide the level of information afforded by $c$-fos as an IEG in the study of acute antidepressant action. In agreement with previous studies, we have shown that all antidepressants induce $c$-fos in the central amygdala and have demonstrated, for the first time, a similar response following acute mirtazapine administration. Additionally, all compounds in the present study induced $c$-fos expression in the anterior insular cortex and decreased $c$-fos expression in the septum, two regions strongly linked with depression in human or animal models. These findings suggest that, while there are different brain regions activated by different antidepressant compounds, it is possible to employ $c$-fos neuronal activity to profile novel antidepressants based on the three common brain regions activated by a number of different classes of antidepressant compounds.

\section{ACKNOWLEDGEMENTS}

DA Slattery was funded by a BBSRC Case Award PhD studentship with Organon Laboratories. We thank Dr Barbara Sumner, Leonie Cruise, and Fiona Adams for their assistance and technical expertise. We also thank Dr John F Cryan and Dr Emma SJ Robinson for their helpful comments on the manuscript.

\section{REFERENCES}

Altschul SF, Gish W, Miller W, Myers EW, Lipman DJ (1990). Basic local alignment search tool. J Mol Biol 215: 403-410.

Bancroft JD, Stevens A (1996). Theory and Practice of Histological Techniques, 4th edn. Churchill Livingstone: New York.

Beck CHM (1995). Acute treatment with antidepressant drugs selectively increases the expression of $\mathrm{c}$-fos in the rat brain. J Psychiatr Neurosci 20: 25-32.

Beckmann AM, Wilce PA (1997). Egr transcription factors in the nervous system. Neurochem Int 31: 477-510.

Chaudhuri A (1997). Neural activity mapping with inducible transcription factors. NeuroReport 8: v-ix.

Cochran SM, McKerchar CE, Morris BJ, Pratt JA (2002). Induction of differential patterns of local cerebral glucose metabolism and immediate-early genes by acute clozapine and haloperidol. Neuropharmacology 43: 394-407.

de Boer T (1996). The pharmacologic profile of mirtazapine. J Clin Psychiatry 57: 19-25.

Dragunow M, Faull R (1989). The use of c-fos as a metabolic marker in neuronal pathway tracing. J Neurosci Methods 29: 261-265.

Drevets WC (1999). Prefrontal cortical-amygdalar metabolism in major depression. Ann NY Acad Sci 877: 614-637.

Drevets WC (2000). Neuroimaging studies of mood disorders. Biol Psychiatry 48: 813-829.

Drevets WC (2001). Neuroimaging and neuropathological studies of depression: implications for the cognitive-emotional features of mood disorders. Curr Opin Neurobiol 11: 240-249.

Drevets WC, Videen TO, Price JL, Preskorn SH, Carmichael ST, Raichle ME (1992). A functional anatomical study of unipolar depression. J Neurosci 12: 3628-3641.

Duncan GE, Knapp DJ, Johnson KB, Breese GR (1996). Functional classification of antidepressants based on antagonism of swim stress-induced fos-like immunoreactivity. J Pharmacol Exp Ther 277: 1076-1089.

Fawcett JA (2003). Lithium combinations in acute and maintenance treatment of unipolar and bipolar depression. J Clin Psychiatry 64: 32-37.

Frazer A (2000). Norepinephrine involvement in antidepressant action. J Clin Psychiatry 61(Suppl 10): 25-30.

Gass P, Herdegen T, Bravo R, Kiessling M (1993). Spatiotemporal induction of immediate early genes in the rat brain after limbic seizures: effects of NMDA receptor antagonist MK-801. Eur J Neurosci 5: 933-943.

Henry B, Crossman AR, Brotchie JM (1999). Effect of repeated LDOPA, bromocriptine, or lisuride administration on preproenkephalin-A and preproenkephalin-B mRNA levels in the striatum of the 6-hydroxydopamine-lesioned rat. Exp Neurol 155: 204-220.

Herdegen T, Leah JD (1998). Inducible and constitutive transcription factors in the mammalian nervous system: Control of gene 
expression by Jun, Fos and Krox, and CREB/ATF proteins. Brain Res - Brain Res Rev 28: 370-490.

Herrera DG, Robertson HA (1996). Activation of c-fos in the brain. Progr Neurobiol 50: 83-107.

Hoffman GE, Lyo D (2002). Anatomical markers of activity in neuroendocrine systems: Are we all 'Fos-ed out'? J Neuroendocrinol 14: 259-268.

Holets VR (1990). The anatomy and function of noradrenaline in the mammalian brain. In: Heal DJ, Marsden CA (eds). Pharmacology of Noradrenaline in the Central Nervous System. Oxford Medical Publications: Oxford. pp 1-40.

Hussy N, Deleuze C, Desarmenien MG, Moos FC (2000). Osmotic regulation of neuronal activity: A new role for taurine and glial cells in a hypothalamic neuroendocrine structure. Progr Neurobiol 62: 113-134.

Kirby LG, Lucki I (1997). Interaction between the forced swimming test and fluoxetine treatment on extracellular 5-hydroxytryptamine and 5-hydroxyindoleacetic acid in the rat. J Pharmacol Exp Ther 282: 967-976.

Labiner DM, Butler LS, Cao Z, Hosford DA, Shin C, McNamara JO (1993). Induction of c-fos mRNA by kindled seizures: Complex relationship with neuronal burst firing. J Neurosci 13: 744-751.

Lamprecht R, Dudai Y (1995). Differential modulation of brain immediate early genes by intraperitoneal LiCl. NeuroReport 7: 289-293.

LeDoux JE, Thompson ME, Iadecola C, Tucker LW, Reis DJ (1983). Local cerebral blood flow increases during auditory and emotional processing in the conscious rat. Science 221: $576-578$

Lino-de-Oliveira C, Sales AJ, Del Bel EA, Silveira MC, Guimaraes FS (2001). Effects of acute and chronic fluoxetine treatments on restraint stress-induced Fos expression. Brain Res Bull 55: 747-754.

Malkani S, Rosen JB (2000). Differential expression of EGR-1 mRNA in the amygdala following diazepam in contextual fear conditioning. Brain Res 860: 53-63.

Morinobu S, Strausbaugh H, Terwilliger R, Duman RS (1997). Regulation of c-Fos and NGF1-A by antidepressant treatments. Synapse 25: 313-320.

Nishina H, Sato H, Suzuki T, Sato M, Iba H (1990). Isolation and characterization of fra-2, an additional member of the fos gene family. Proc Natl Acad Sci USA 87: 3619-3623.

Nofzinger EA, Berman S, Fasiczka A, Miewald JM, Meltzer CC, Price JC et al (2001). Effects of bupropion SR on anterior paralimbic function during waking and REM sleep in depression: preliminary findings using. Psychiatry Res 106: 95-111.

O'Donovan KJ, Tourtellotte WG, Millbrandt J, Baraban JM (1999). The EGR family of transcription-regulatory factors: progress at the interface of molecular and systems neuroscience. Trends Neurosci 22: 167-173.

Ongur D, Price JL (2000). The organization of networks within the orbital and medial prefrontal cortex of rats, monkeys and humans. Cerebral Cortex 10: 206-219.
Paxinos G, Watson C (1986). The Rat Brain in Stereotaxic Coordinates 2nd edn, Academic Press: New York.

Ronan PJ, Steciuk M, Kramer GL, Kram M, Petty F (2000). Increased septal 5-HIAA efflux in rats that do not develop learned helplessness after inescapable stress. J Neurosci Res 61: 101-106.

Sagar SM, Sharp FR, Curran T (1988). Expression of c-fos protein in brain: metabolic mapping at the cellular level. Science 240: $1328-1331$.

Salchner P, Singewald N (2002). Neuroanatomical substrates involved in the anxiogenic-like effect of acute fluoxetine treatment. Neuropharmacology 43: 1238-1248.

Sherman AD, Petty F (1980). Neurochemical basis of the action of antidepressants on learned helplessness. Behav Neural Biol 30: 119-134.

Singewald N, Salchner P, Sharp T (2003). Induction of c-Fos expression in specific areas of the fear circuitry in rat forebrain by anxiogenic drugs. Biol Psychiatry 53: 275-283.

Singewald N, Sharp T (2000). Neuroanatomical targets of anxiogenic drugs in the hindbrain as revealed by Fos immunocytochemistry. Neuroscience 98: 759-770.

Slattery DA, Hudson AL, Nutt DJ (2004). Invited review: the evolution of antidepressant mechanisms. Fundam Clin Pharmacol 18: 1-21.

Spencer CM, Houpt TA (2001). Dynamics of c-fos and ICER mRNA expression in rat forebrain following lithium chloride injection. Mol Brain Res 93: 113-126.

Steciuk M, Kram M, Kramer GL, Petty F (1999). Decrease in stressinduced c-Fos-like immunoreactivity in the lateral septal nucleus of learned helpless rats. Brain Res 822: 256-259.

Sumner BE, Cruise LA, Slattery DA, Hill DR, Shahid M, Henry B (2004). Testing the validity of c-fos expression profiling to aid the therapeutic classification of psychoactive drugs. Psychopharmacology (Berlin) 171: 306-321.

Thiriet N, Zwiller J, Ali SF (2001). Induction of the immediate early genes egr- 1 and $c$-fos by methamphetamine in mouse brain. Brain Res 919: 31-40.

Torres G, Horowitz JM, Laflamme N, Rivest S (1998). Fluoxetine induces the transcription of genes encoding c-fos, corticotropinreleasing factor and its type 1 receptor in rat brain. Neuroscience 87: 463-477.

Zangenehpour S, Chaudhuri A (2002). Differential induction and decay curves of c-fos and zif268 revealed through dual activity maps. Mol Brain Res 109: 221-225.

Zerial M, Toschi L, Ryseck RP, Schuermann M, Muller R, Bravo R (1989). The product of a novel growth factor activated gene, fos $\mathrm{B}$, interacts with JUN proteins enhancing their DNA binding activity. EMBO J 8: 805-813.

Ziolkowska B, Przewlocki R (2002). Methods used in inducible transcription factor studies: focus on mRNA. In: Kaczmarek LK, Robertson HA (eds). Handbook of Chemical Neuroanatomy (Immediate Early Genes and Inducible Transcription Factors in Mapping of the Central Nervous System Function and Dysfunction). Elsevier: Amsterdam. pp 1-38. 